\title{
QUESTÕES DA DISFORIA DE GÊNERO NA INFÂNCIA: ENTRE PSICANÁLISE E MEDICINA
}

\author{
Issues of Gender Dysphoria in Childhood: Between Psychoanalysis and Medicine \\ Cuestiones de la Disforia de Género en la Niñez: Entre Psicoanálisis y Medicina \\ Problèmes de Dysphorie de Genre chez l'Enfant : Entre Psychanalyse et Médecine \\ doi $10.5020 / 23590777 . r s . v 20 i E s p 2 . e 8822$
}

\begin{abstract}
Sonia Alberti 9 iD
Professora Titular e Procientista da Universidade do Estado do Rio de Janeiro (UERJ). Pesquisadora do CNPq. Preceptora da Residência em Psicologia Clínica Institucional do Instituto de Psicologia da UERJ. Psicanalista Membro da Escola de Psicanálise dos Fóruns do Campo Lacaniano.

\section{Heloene Ferreira da Silva 9 iD}

Doutoranda em Psicanálise PGPSA/UERJ, bolsista FAPERJ. Mestre em Psicanálise PGPSA/UERJ. Especialista em Psicologia Clínica Institucional modalidade Residência Hospitalar HUPE/UERJ.
\end{abstract}

\section{Resumo}

No que tange à psicanálise, qual é nossa política diante das questões de gênero? Eis a pergunta que esse texto se coloca a partir do trabalho com uma criança encaminhada para diagnóstico após a suspeita da pediatra de que seria portadora de uma disforia de gênero. Retomando as diretrizes que orientam a medicina quanto à questão na atualidade, observando o trabalho analítico dessa criança e situando-nos frente a observações cruciais, tanto de Freud quanto de Lacan, sobre a postura do analista quanto às questões das subjetividades de sua época, discutimos a falácia da binaridade que vige em um mundo biologizante. Orientamo-nos, metodologicamente, de duas formas: a discussão de discursos e o trabalho clínico conforme a pesquisa em psicanálise, isto é, fazer o sujeito falar para, a partir daí, construir possíveis balizas para sua própria identidade, dessa forma é possível atualizar a referência freudiana ao impossível.

Palavras chave: gênero; sexuação; caso clínico; medicina e psicanálise.

\section{Abstract}

Concerning psychoanalysis, what is our policy regarding gender issues? This is the question that this text raises from the work with a child referred for diagnosis after the pediatrician's suspicion that she would have gender dysphoria. Resuming the guidelines that guide medicine regarding the issue today, observing the analytical work of this child and situating ourselves in the face of crucial observations, both by Freud and Lacan, on the analyst's stance on the issues of the subjectivity of his time, we discussed the fallacy of binarity that prevails in a biologizing world. We are guided, methodologically, in two ways: discourse discussion and clinical work according to research in psychoanalysis, that is, making the subject speak to, from there, build possible beacons for their own identity, so it is possible to update the Freudian reference to the impossible.

Keywords: gender; sexuation; clinical case; medicine and psychoanalysis.

\section{Resumen}

Lo que se refiere al psicoanálisis, ¿cuál es nuestra política ante las cuestiones de género? Esta es la pregunta que este texto pone a partir del trabajo con un niño direccionado para diagnóstico después de la sospecha de la pediatra de que sería portadora de una disforia de género. 
Retomando las directrices que orientan la medicina cuanto a la cuestión en la actualidad, observando el trabajo analítico de este niño y ubicándonos ante observaciones cruciales, tanto de Freud cuanto de Lacan, sobre la postura del analista cuanto a las cuestiones de las subjetividades de su época, discutimos la falacia de la binaridad que existe en un mundo biologizante. Nos orientamos, metodológicamente, de dos formas: la discusión de discursos y el trabajo clínico según la investigación en psicoanálisis, es decir, hacer el sujeto hablar para entonces construir posibles balizas para su propia identidad, de esta forma es posible actualizar la referencia freudiana al imposible.

Palabras clave: género; sexualización; caso clínico; medicina y psicoanálisis.

\section{Résumé}

Dans ce qu'il concerne à la psychanalyse, quelle est notre politique devant la matière de genre ? Voici la question que ce texte soulève à partir du travail avec un enfant dont le pédiatre soupçonne qu'il aurait une dysphorie de genre. Nous avons discuté de l'illusion de la bicatégorisation en reprenant les lignes directrices qui guident la médecine sur cette question aujourd'hui, en observant le travail analytique de cet enfant et en nous situant face à des observations cruciales de Freud et, aussi, de Lacan, sur la position de l'analyste sur les enjeux de subjectivité de son temps. Nous sommes guidés, méthodologiquement, de deux manières : par des débat sur les discours et par le travail clinique, selon la recherche en psychanalyse, c'est-à-dire faire parler le sujet et, donc, construire des balises possibles pour sa propre identité. Par conséquent, il est possible de mettre à jour la référence freudienne à l'impossible.

Mots-clés : sexe ; sexuation ; cas clinique ; médecine et psychanalyse.

As coisas não querem mais ser vistas por pessoas razoáveis:

Elas desejam ser olhadas de azul Que nem uma criança que você olha de ave. Manoel de Barros (2016).

Pabllo Vittar emerge, em 2017, como a drag queen mais famosa do país, ao mesmo tempo em que uma novela, em horário nobre, aborda a questão da transsexualidade. Estamos diante de uma nova revolução sexual, à altura daquela que se iniciou nos anos 1960, introduzindo a liberação sexual, com a aceitação social do sexo antes do casamento, a partir da comercialização da pílula - e da legalização do aborto em vários países desenvolvidos do ocidente. Alastrou-se década de 1970 adentro, a partir dos movimentos iniciados em 1969, no bar Stonewall, em Nova Iorque, quando membros da comunidade LGBT insurgiram-se contra as contínuas agressões da polícia de Nova York em represália à homo-sensualidade permitida no bar e suas adjacências. A contracepção, a nudez, a homossexualidade e as formas alternativas de sexualidade, de modo geral, assim como a legalização do aborto, foram resultado de lutas pelos direitos de cada cidadão escolher sua própria forma de gozar e se instrumentalizar do corpo, o que não deixa de ser um ato político se, como Aristóteles, entendemos o homem como um animal cuja própria natureza é política e se, com Hobbes - que, como Freud (1930/1974), retomou a máxima de Plauto segundo a qual o homem é o lobo do homem -, entendemos que, na política, é necessário um pacto - ou contrato - social para que reine paz suficiente entre os homens, de modo a que os mais fracos e desassistidos possam se ver protegidos dos mais fortes (e.g. Fraga, 2014). Parafraseando Lacan (2006), poderíamos afirmar que a sexualidade é a política! A partir de Laufer (2017), poderíamos então questionar: tocar a ordem sexuada tem mais consequências do que tocar a ordem econômica ou política do país?

$\mathrm{O}$ texto que segue é um produto do trabalho que desenvolvemos em nossa pesquisa de doutorado e que tange as atuais questões de gênero, visando a verificar a posição que a psicanálise pode assumir ali onde Jacques Lacan (1998a, p. 322) propõe que é preciso que o psicanalista "alcance em seu horizonte a subjetividade de sua época".

No que tange à psicanálise, qual é nossa política? Será que estamos aptos a interrogar como crianças andróginas e bissexuais são transformadas em meninos ou meninas (Laufer, 2017)? Ou fiamo-nos no referencial biológico e reiteramos toda designação sexual advinda no momento do nascimento pelo marcador anatômico? Que espaço há em nossas clínicas para sustentarmos o irrepresentável do sexo quer ele apareça em que idade for? O que é isso que estamos escutando? Se, hoje, o saber se escreve em termos de ou/ou, nem/nem, se/então..., nós, psicanalistas, reforçamos essa dicotomia? Quanto nos aferramos ao binário? Se muitos ainda confundem escolha de objeto e posição sexuada, como podemos avançar? Se "a contratransferência nada mais é do que a função do ego do analista, o que chamei a soma dos preconceitos do analista" (Lacan, 1996, p. 33. Grifo nosso), essa contratransferência poderia ocorrer também em relação à teoria? 


\section{Método}

Partindo de um caso clínico encaminhado para diagnóstico psicológico por uma pediatra que suspeitava de "uma disforia de gênero" em uma criança de quatro anos de idade que dizia ser menina quando, pelo menos do ponto de vista anatomofisiológico, era um menino, inúmeras questões surgiram em relação à abordagem teórica dessa questão absolutamente contemporânea. Em consequência, examinamos: 1) o ponto de vista médico que levou a pediatra a fazer o encaminhamento do caso, 2) a clínica que questiona a teoria, permitindo enriquecê-la, 3) como nos colocar ao trabalho por uma elaboração teórica que objetiva a pesquisa em psicanálise.

Desde sempre, a recomendação freudiana é de que, quando temos um caso em análise, não devemos colocá-lo antecipadamente em uma categoria e, como também dizem Giaretta \& Silva (2019, p. 143), nosso trabalho se configura "aberto, inventivo, espontâneo e fecundo, longe de corresponder a uma espécie de protocolo de intervenções". Lacan (1975, p. 11. [Tradução nossa]) comenta: "que escutemos com total independência em relação a todos os conhecimentos adquiridos por nós", para que nos dediquemos à particularidade do caso.

Assumimos o caso, como analista e supervisora, desde que orientadas pela metodologia freudiana do trabalho clínico: fazer falar e, assim, promover a presentificação do sujeito, construir alguma coisa. O fazer falar (Celes, 2005) implica em levar em conta que o sujeito é aquele que fala (Lacan, 1998a), pois ele aí se presentifica por meio dos próprios significantes que emite e, ao contrário de nos situarmos diante disso numa suposta contratransferência - que, como o bem disse Lacan (1996), não passa de uma transferência -, devemos deixar nos surpreender pelo novo de cada caso.

Orientamo-nos, metodologicamente, portanto, de duas formas: de um lado, a discussão dos discursos sobre a disforia de gênero na infância e, de outro, o trabalho clínico conforme a pesquisa em psicanálise: fazer o sujeito falar para, a partir daí, construir possíveis balizas para sua própria posição subjetiva.

Fiamo-nos na assertiva de Jacques Lacan $(1992$, p, 82) de que "a configuração subjetiva tem, pela ligação significante, uma objetividade perfeitamente localizável, que funda a própria possibilidade da ajuda que trazemos sob a forma da interpretação". Partimos de uma revisão bibliográfica, cotejamos o produto de tal revisão com a clínica, e levantamos, então, hipóteses para possíveis avanços teóricos.

\section{Justificativa}

A WPATH (Associação Mundial Profissional para a Saúde Transgênero), cujas Normas de atenção à saúde das pessoas trans e com variabilidade de gênero (WPATH, 2012) funcionam como referência internacional para os protocolos médicos, ressaltam, na seção VI, relacionada à avaliação e tratamento de crianças e adolescentes com disforia de gênero, que, na história clínica da maioria das crianças com disforia, verifica-se que, ao chegarem à puberdade, tal disforia terá desaparecido. "No entanto, em algumas crianças, esses sentimentos se intensificam, e a aversão ao corpo se desenvolve ou aumenta à medida que chegam à adolescência e suas características sexuais secundárias se desenvolvem" (WPATH, 2012, pp. 13-14).

A WPATH observa que a conduta e tratamento médico precoce variam conforme a legislação de cada país e que, no caso de um país adotar o tratamento precoce, ele consiste na administração de hormônios bloqueadores da puberdade nos primeiros estágios de Tanner (escala de medição de desenvolvimento da puberdade). A WPATH alerta para o fato de que médicos inexperientes "podem confundir sinais de disforia de gênero com delírios" (WPATH, 2012, p. 14), quando, na realidade, a disforia de gênero possui um diagnóstico independente de qualquer afecção mental, pois a "grande maioria das crianças e adolescentes com disforia de gênero não está sofrendo de uma doença psiquiátrica grave subjacente" (WPATH, 2012, p. 14). Surge daí a necessidade de o profissional ser "experiente no diagnóstico e tratamento dos problemas comuns de crianças e adolescentes", o que levou a American Psychological Association (APA, 2015) a lançar o Guidelines for psychological practice with transgender and gender nonconforming people, cuja proposta era contribuir nessa formação de profissionais da saúde, e a Turban, Ferraiolo, Martin, e Olezeski (2017) a publicarem em artigo com dez itens para orientar médicos e psicólogos no trato com crianças e adolescentes que apresentarem questões de disforia de gênero. Entre essas dez orientações, lê-se, explicitamente, em seu item 7, que o "bloqueio de puberdade e esteroides sexuais podem salvar a vida" de um pré-adolescente (Turban et al., 2017, p. 276, Tradução livre).

Eis, então, a razão pela qual a pediatra que encaminhou o caso que trabalharemos buscava um diagnóstico psicológico mais apurado: tentar identificar, de forma bastante precoce, se, ao crescer, essa criança deveria ou não ser submetida a bloqueio de puberdade, a fim de evitar-lhe futuro sofrimento diante da natural aquisição dos caracteres sexuais secundários e do crescimento dos órgãos sexuais de sua anatomofisiologia. Diante de tal pedido, que política a psicanálise deve adotar?

Sabemos que boa parte da estratégia de instalação da psicanálise na cultura se dá a partir de um discurso no qual ela se coloca na contramão da desvalorização do que está fora da norma, a ponto de haver psicanalistas que afirmam que a psicanálise a contraria (Ambra, 2016). Retomemos a passagem em que Lacan não apenas o corrobora, como o explicita, dirigindo-se aos analistas de uma forma geral: 
O que eu tento é outra coisa. É fazer com que, no seu discurso, vocês ponham menos bobagens [...], e que, para isso, tentem arejar um pouco o sentido com elementos que sejam meio novos. Está muito claro que não há nenhum meio de separar duas séries quaisquer - eu disse quaisquer - de atributos que componham uma série masculina, de um lado, e a série feminina, do outro. (Lacan, 2012, p. 178)

O psicanalista, ao introduzir o sujeito na cena, está advertido de que o próprio "sujeito é o real da ordem social" (Elia, 2005, p. 5), marcando também o estatuto do lugar da psicanálise em relação ao saber médico, na medida em que ela surge e sobrevive até hoje, resistindo à tentativa sempre fracassada do saber científico de escrutinar o corpo humano e enquadrá-lo no território das taxionomias.

Há que se precisar a ética do psicanalista, mas, ao mesmo tempo, talvez essa seja uma das maiores dificuldades em implementar uma parceria entre a prática médica e o ato psicanalítico: a diferença ética. Freud já alertava, como escreve Figueiredo (1997, p. 73), "para a ineducabilidade das pulsões" (pilar da psicanálise) e, de outro lado, para os perigos do "furor sanandi" (perigo da medicina), questões que escapam totalmente à ciência médica, pois implicam a prática da teoria psicanalítica. Pudemos observar a função da psicanálise junto à medicina: a de participar de um ato clínico que, no avesso da categorização normativa, recupera o olhar como dedicado à particularidade de cada caso (Alberti, 2000).

\section{Caso Clínico}

Quando recebemos a demanda de tratamento para Nicolas - nome fictício -, um menino de quatro anos que, segundo a mãe, queria ser uma princesa e gostava de brincar que estava grávido, sustentamos uma não resposta imediata, imprimindo na condução do caso a assunção do lugar atópico que o analista deve ocupar. Se a clínica psicanalítica deve ir além da estrutura (Braunstein, 2016), não sem levá-la em conta, de que maneira podemos nos orientar? Lacan (2005) nos ensina que, sem a experiência clínica, a teoria não passa de um ajuntamento.

Lindo, franzino e muito inteligente, aos quatro anos de idade, Nicolas quer sair de casa fantasiado de Frozen, usar saias e vestidos, passar batom, brincar de bonecas e de estar grávido. Em suas primeiras palavras, afirma que quer ser uma princesa, "porque as princesas são lindas"! Nas entrevistas com os pais, ambos relatam que, logo após seu nascimento, sentiram um amor imenso e inexplicável por aquele bebezinho. "Eu tinha que me controlar para não fazê-lo só meu. Não queria dividir ele com ninguém. Achava que só eu sabia cuidar", disse a mãe. "Quando o vi, descobri o que era amor de verdade. Minha mulher, naquele momento, já podia ir embora... Ela foi apenas a hospedeira do verdadeiro amor da minha vida", disse o pai. Curiosamente, nenhum dos dois parecia se importar com o fato de terem gerado um filho tardiamente no casamento. A explicação de cada um para ter chegado a hora de gerarem Nicolas foi: “O meu relógio biológico tocou”, disse a mãe. "Ah, era isso que a sociedade esperava de mim", disse o pai.

Os pais discordam e assumem posturas muito diferentes em relação ao possível diagnóstico médico do filho, que eles identificavam como "transtorno de identidade de gênero", o que é uma nosologia do DSM IV, criticada por ter sido considerada um transtorno e, por isso, retificada no DSM V como "disforia de gênero". Para a mãe, o filho é uma criança muito especial, muito sensível e, por isso, muito ligado ao feminino, sendo "um dom dele mesmo que não podemos mudar", ela diz. Para o pai, o filho "foi contaminado" por ter crescido cercado de mulheres e por não ter ninguém que "corte essas coisas de princesa e incentive outras coisas", ele diz.

Contam que só tiveram coragem de pedir ajuda agora porque perceberam que o filho estava sendo hostilizado: suas amiguinhas da escola dizem para ele que ele é menino e não pode fazer festa de princesa; ele não entende o porquê. Com os meninos ele responde de forma agressiva, "rola porrada, porque ele é muito territorialista", diz o pai orgulhoso. Os pais contam que sempre o mimaram: "nós o mimamos muito. Mimamos sabendo que estávamos mimando. Mimamos sem poder parar de mimar". Além disso, na internet, a mãe estudou várias teorias sobre como criar um filho e encantou-se com aquela que apregoava a "criação com apego" (da API - Attachment Aperenting International), que dita que o bebê possui três necessidades básicas: proteção, previsibilidade e proximidade, e que, quando essas necessidades são atendidas, ele se desenvolve de forma "plena e feliz".

A avó paterna também mima Nicolas, dá bonecas de presente, e não fica abalada com as manifestações de Nicolas de que é princesa, quer brincar de boneca e ter um bebê, porque, como a própria avó diz, "o pai também era bichinha quando criança". O pai ratifica: "sempre fui muito bobo e chorão", e acrescenta que atravessou a adolescência com dificuldades, mas, quando chegou à vida adulta, se viu um homem bonito e forte e "aí, arrasava na performance. Garanhão pegador!"

Em sua primeira entrevista sozinho, Nicolas diz que vai desenhar a analista igual a uma princesa, a princesa mais linda, que é a Frozen, com trança e tudo, mas, quando vai desenhar, faz um chapéu de bruxa e diz a seu desenho: "agora, você é a Rainha Má". Tira a tampa de todas as canetinhas que lhe oferece a analista para desenhar e risca seus braços, pernas e rosto. 
Fica todo rabiscado e, quando a analista lhe faz perguntas, ele responde apenas com cocô e xixi. Cedo percebemos que Nicolas transfere o binarismo que ele presentifica como um dois em um para todas as coisas com as quais se ocupa - cocô e xixi -, e cedo também o que é a mais linda das princesas pode se tornar Rainha Má, indiferentemente se ela é ele próprio ou sua analista.

Ainda nas primeiras entrevistas, fala sobre sua segunda grande paixão, o desenho Ever after high - produzido em parceria com a Mattel e Netflix -, "no qual as princesas são valentes". No desenho, as filhas adolescentes das princesas e vilãs de Disney estão em conflito. Enquanto Apple White (filha da Branca de Neve) quer cumprir seu destino de "viver feliz para todo o sempre", Raven Queen (filha da Rainha Má) recusa-se a cumprir seu destino de tornar-se uma vilã como sua mãe. Raven prefere criar seu próprio destino, enquanto Apple acredita que, para realizar seu sonho, Raven deve seguir o dela e se tornar a nova Rainha Má. Nicolas, a princípio, identifica-se com a Rainha Má, inclusive, foi essa a boneca que ele pediu e ganhou do Papai Noel no último Natal.

Enquanto a mãe o descreve como "muito sensível e delicado", Nicolas tem atos autoagressivos, alguns mutilantes, como quando arrancou grande parte de seu cabelo pela raiz para livrar-se da cola colorida que nele secara - ato que a mãe achou muito engraçado.

Numa sessão, os pais trazem Antonia, a carismática irmã de Nicolas. Uma menina muito afetuosa que, embora ainda não fale, espalha todo seu charme e felicidade. Nicolas a empurra, aperta seu braço, bate nela... E ela e os pais apenas sorriem. Até que Nicolas risca o rosto da irmã com muita força, ela chora. Os pais nada dizem a Nicolas, pegam Antonia e fazem-na parar de chorar. Eles insistem em dizer que Nicolas é um irmão maravilhoso e muito cuidadoso com a irmã, que nunca sentiu ciúmes dela. Afinal, durante a gestação de Antonia, eles foram muito bem preparados pelo ginecologista que fazia o pré-natal, que contou a seguinte metáfora para a mãe: "imagina que o Antony [nome fictício do pai de Nicolas e Antonia] vai chegar em casa com uma nova esposa e essa nova esposa vai dividir com você tudo que era só seu. É assim que o Nique [apelido que aqui lhe damos para fazer ressoar aquele com o qual é chamado em casa] irá se sentir"...

Nas sessões, Nicolas escolhe sempre brincar com as bonecas e deixa os bonecos com a analista. Todos os personagens peidam e fazem cocô o tempo todo. Entre uma fala e outra, Nicolas grita, debate-se, rabisca-se, come papel, espalha todos os brinquedos, joga-se da cadeira... Numa dessas "crises", ele diz: "eu deixo a xxx (nome da analista) doidinha".

Nicolas costuma dizer que o cabelo da analista é igual ao da Branca de Neve, rival direta da Rainha Má no desenho que adora assistir. Ele diz que irá espioná-la pelo espelho que ele tem em casa, no qual conseguirá ver tudo o que a analista faz. As crises de autoagressividade ainda são constantes, e ele se risca, grita... A analista diz: "você pode ficar tranquilo aqui. Aqui nada irá lhe fazer mal". Ele responde: "você não me conhece".

Na sessão seguinte, Nicolas diz: "eu tenho uma pepeca no lugar do lulu". "É sério? E como é isso?", questiona a analista. "Ah, eu tenho um lulu na frente e uma pepeca atrás. Uma pepeca e um lulu juntos". A representação do órgão genital como dois em um sugere reflexões teóricas importantes. E uma pergunta se impõe: seria possível que esse trans Nicolas identifique a sexualidade com o mesmo maniqueísmo característico de uma tentativa holofrásica de mapear o mundo que pode ocorrer na psicose? Ou seria apenas uma forma de se fazer amar ali onde sua mãe dele não se pode separar?

Nicolas passa sessões respondendo somente cocô e xixi. Até que, em uma sessão, diz que precisa fazer cocô e vai ao banheiro. Na saída da sessão, ele diz: "o cocô foi dividido. Agora está metade na cabeça da mamãe, metade na sua cabeça". Aos poucos, Nicolas suporta alguma divisão.

Certa feita, a mãe chega rindo e diz à analista: "não sei se eu deveria estar rindo da história que vou te contar". Conta que Nicolas e uma amiguinha foram para o canto da sala de aula na escola e que ele teria tocado a "pepeca" dela. Ao assisti-la contando-a para a analista, Nicolas fica furioso, chora, faz birra, diz que quer ir embora. Percebendo-o, a analista se senta a seu lado e diz: "te esperei a semana toda e agora que você está aqui, você não quer falar comigo? Eu gosto tanto de falar com você. O que houve"? Ele ri e vai pegar os brinquedos. Desenha uma menina e pergunta: "xxx (nome da analista), você me ama?" e desenha um coração. Mas antes mesmo que a analista possa responder alguma coisa, ele diz: "eu te amo!", e desenha o outro coração.

Após algumas sessões e muitas supervisões clínicas, a analista pergunta a Antony, pai de Nicolas, se ele sabe a importância de um pai na vida de um filho. Surpreso, ele responde que sim, mas depois pensa e questiona: "qual é a resposta certa"? Perguntado sobre se ele acredita que há uma resposta certa, ele responde: "eu não sei". Essa entrevista marca uma retificação na postura do pai. Ele passa a estar mais em casa e incluir o filho em suas atividades. Eles saem para fazer "coisas de meninos" e o pai passa a aceitar a paixão do filho por Moana, personagem de outro filme da Disney, e lhe traz essa boneca de uma das viagens que faz ao exterior.

Numa sessão posterior, a analista tinha mudado seus cabelos, agora cacheados. Nicolas não parava de olhá-la, boquiaberto. Então, ele diz: "você é da família da Moana. Você é moreninha. Eu sou moreninho. Nós somos da família da Moana". Nicolas passa, então, a se identificar com Moana, a mais recente princesa da Disney, aliás, cabe dizer, uma tentativa da Disney de afastar as princesas dos papéis estereótipos de gênero. Moana ganha grande espaço em sua vida. Falando seu inglês perfeito, Nicolas canta afinadamente a música tema da princesa: 
Tento obedecer, não olhar pra trás / Sigo meu dever, não questiono mais / Mas pra onde vou, quando vejo, estou onde eu sempre quis / O horizonte me pede pra ir tão longe

Será que eu vou? / Ninguém tentou / Se as ondas abrirem pra mim de verdade / Um dia eu vou saber quem sou.

Sua mãe conta que o parto de Nicolas fora por cesárea. Em suas palavras, "ter feito uma cesárea não foi parir. Cesárea não é parto, é cirurgia de extração de feto". Diz que apenas com o nascimento da filha se tornou uma "mulher de verdade". Conta que parir é a coisa mais maravilhosa do mundo. "As outras que me desculpem, mas uma mulher que não pare de parto natural não é uma mulher de verdade. Tem que abrir as pernas e colocar a criança no mundo para saber como é que é uma coisa plena. Um orgasmo".

Foi quando essa irmã completou um ano de idade que Nicolas passou a querer ser uma princesa. Uma princesa que usa batom, vestidos, saltos e acessórios da mãe. Um "Himeneu travestido assistindo a uma dança em honra de Príapo", cena do quadro de Poussin (1634/1638), que mostra o deus grego do casamento vestido de mulher numa dança para Príapo, o deus da fertilidade, que costuma ser representado com o falo em perpétua ereção. O jovem Himeneu era tão belo que se dizia parecido com uma moça, e transveste-se para ficar junto a sua amada num ritual somente acessível a mulheres. Assim também o querer ser de Nicolas não diz respeito a uma escolha de objeto e, sim, a uma busca de ser. Separado e amado.

Com o andar da análise de Nicolas, a mãe relata ter percebido uma grande mudança no comportamento do filho. "Ele agora é um menino confiante, que consegue conviver bem com qualquer criança". Conta que, em casa, ela sempre imagina: "O que a xxx (nome da analista) me diria se estivesse aqui vendo o que estou fazendo"?, e que esse pensamento a ajuda a ter um pouco de tranquilidade. O pai fala da sua satisfação em ver como o filho cresceu e como está cada dia mais independente. Nas sessões, Nicolas se dedica a desenhar, cantar, jogar, falar sobre Moana.

A crise financeira enfrentada pelos pais chega a seu ápice e eles são obrigados a mudar os padrões de vida e reduzir os gastos. Optam por retirar Nicolas do tratamento. Na última sessão, quem traz Nicolas é o pai. Sem saber como abordar o assunto e visivelmente consternado, ele começa dizendo que o filho não queria mais vir por que não conseguiria ficar sozinho no consultório sem os pais. Nesse momento, o pequeno analisante sugere desenharmos juntos. Ele pede para que a analista o desenhe e ele desenha seu vestido de Rainha Má. Pede para que a analista escreva seu nome completo e, pela primeira vez, acrescenta o sobrenome da mãe ao seu. Pede que a analista escreva o nome do país onde o avô paterno nasceu e diz que irá se mudar para lá. "Lá é frio, tem neve e fica muito longe daqui”. A analista diz: "parece que ficaremos um bom tempo sem nos vermos... Eu queria te pedir para me contar uma história, assim, quando nos reencontrarmos, a gente continua". Nicolas não pensa duas vezes e diz: "vou te contar a história do homem grávido":

Teria uma menina gorda.

Ele comeu muita coisa e ficou grávido.

Vão cortar a barriga dele.

Ele vai virar um sapo.

A Antonia estava dentro da barriga do papai.

Inúmeras são as observações que podemos fazer sobre esse caso, à luz da clássica teoria da clínica psicanalítica: a dificuldade da mãe diante do parto, e nos dois sentidos do termo; a importância da transferência na clínica com crianças, inclusive envolvendo o casal parental; a entrada da analista na relação do pai com o filho, quando esse pai é tão determinado pela sua relação com a própria mãe, para a qual era uma bichinha, a ponto de ele ter que se transvestir de garanhão, distanciandose, assim, de sua própria família, viajando o tempo todo, o que só foi modificado quando, com a analista do filho, pôde se colocar na função paterna, tão importante para Nicolas.

Além disso, todo o trajeto analítico feito pelo pequeno analisante, que da binaridade do cocô e xixi desliza para a pepeca e o lulu, numa tentativa de integrar, em si mesmo, a delicadeza com que era identificado pela mãe e a agressividade que extravasava na lida com os meninos e com ele próprio. Mas, de tudo isso, o que insere o caso Nicolas na clássica clínica com crianças, a questão que o trouxe para o consultório da analista, é, absolutamente, contemporânea.

\section{Criança é Trans? Prolegômenos Psicanalíticos}

Dos nossos antecedentes, podemos afirmar que a sexualidade é infantil, "perverso polimorfa", e se constitui na relação com o Outro, desde os tempos de Freud (1905/2016). Nisso não há nada de novo debaixo do sol. Contudo, a racionalidade clínica hegemônica de nosso tempo procura, por meio de sua especialização nos ramos da biologia molecular, determinar de modo inequívoco a realidade do sexo do sujeito. Uma clínica médica atravessada por uma perspectiva que se diz científica por propor métodos neutros e resultados universais, mas que desconsidera, na realidade, a possibilidade de as questões envolvidas 
atravessarem outros campos que não apenas o da biologia molecular, porque o sujeito não é totalmente submetido ao que encontra a ciência, menos ainda, o sujeito é inequívoco. O que esse modelo de pensamento esquece, é que a realidade do sexo se dá em sua "relação com a alteridade, em que para ele [o sujeito] consistem a linguagem, a família, a sociedade, enfim, todos os elementos do que Lacan denominou o Outro, que o sujeito vai sexuar-se, definir-se homem ou mulher, e definir também os seus demais atributos" (Elia, 2000, p. 26). Logo, essa racionalidade ávida por determinar o sexo independentemente do sujeito se esquece, indiscutivelmente, da clínica e do fato de que o sujeito, por definição, é dividido.

Sobre o fenômeno chamado "infância trans" (Tajer, 2017), a psiquiatria diz: é trans! A mídia, redutora de complexidades, é reducionista e afirma: já nasceu assim! De tal maneira que, multiplicam-se os analistas de Facebook, de Youtube, de Veja. Colocando suposições quando não há clínica.

A partir da escuta analítica de sujeitos transsexuais participantes do processo transsexualizador no SUS, chama a atenção isso que eles dizem ser um sentimento tão precoce, como na fala de Karina (nome fictício), transmulher de 52 anos, que espera na fila da cirurgia de transexualização há seis anos:

Eu sempre achei que eu fosse uma mulher. Quando eu era pequena, eu achava que todas as mulheres tinham o que eu tinha. Eu via $\boldsymbol{a}$ das minhas irmãs e imaginava que $\boldsymbol{o}$ delas iria crescer. Aí, quando eu fiz sete anos, eu me apaixonei pelo irmão da amiga da minha irmã. Eu sempre tive cabelo comprido, usava roupas leves e coloridas, brincava de pique, comidinha, bola... Eu não sabia que eu não era uma mulher... até que eu beijei esse menino. Ele contou para a mãe dele e, a partir dali, todos me diziam todos os dias que eu não era uma mulher, mas eu era, eu sou e eu sempre vou ser. [...] A cirurgia é só para me dar uma vagina com a qual eu já deveria ter nascido.

Karina afirma que, antigamente, não havia esse negócio tão bem definido de "isso é coisa de menina" e "isso é coisa de menino". Segundo ela, a infância era muito mais colorida do que as hodiernas divisões binárias rosa ou azul, boneca ou carrinho, balé ou futebol... Atualmente, um menino que goste de princesas, rosa, laços de cabelo, colocar saia e sapato alto será considerado uma criança transgênero. Uma menina que goste de só usar calças, cabelo curto, futebol e de brincadeiras agressivas, será igualmente trans. Mas e se nenhuma dessas coisas fossem "de menino" e "de menina"?

No âmbito dos estudos de gênero contemporâneo, Preciado (2014) - que em entrevista deu a seguinte declaração: "Se sou homem ou mulher? Esta pergunta reflete uma obsessão ansiosa do ocidente. Qual? A de querer reduzir a verdade do sexo a um binômio. Eu dedico minha vida a dinamitar esse binômio. Afirmo a multiplicidade infinita do sexo"! -, trabalha para desmascarar os binarismos enganosos que se escondem por trás de oposições que servem não só "de fundamento da filosofia moderna", mas também como "reflexão das teorias feministas" (Bourcier, 2014, p. 11).

Seu Manifesto contrassexual enfatiza o corpo como espaço de construção biopolítica, como lugar de opressão, mas também como centro de resistência. A autora poderia ser alocada na corrente pós-feminista que concebe o sujeito como uma posição instável, como o efeito de constantes renegociações estratégicas de identidade, no entanto Preciado avança e postula o gênero não como simplesmente performativo, mas, "antes de tudo, prostético, ou seja, não se dá senão na materialidade dos corpos. É puramente construído e, ao mesmo tempo, inteiramente orgânico. [...] poderia resultar em uma tecnologia sofisticada que fabrica corpos sexuais" (Preciado, 2014, p. 29).

Preciado tem toda razão! Assim como Karina. A binaridade entrou no discurso de forma avassaladora na contemporaneidade: “antigamente, não havia esse negócio tão bem definido de 'isso é coisa de menina' e 'isso é coisa de menino'[...] a infância era muito mais colorida do que as hodiernas divisões binárias rosa ou azul, boneca ou carrinho, balé ou futebol...”. Inúmeras culturas que não se situam no discurso cientificista ainda hoje testemunham a pluralidade de posições subjetivas ou, como afirma Preciado, "a multiplicidade infinita do sexo"! A questão era bem mais nebulosa, e a criança era, sim, informada que havia uma diferença entre meninos e meninas, mas não se falava disso a todo momento. Pretender não influenciar a criança na orientação de sua identidade de gênero é efeito do encontro do discurso da ciência com a biologização do homem e da mulher, ou seja, do discurso capitalista, que pretende vender hormônios, cirurgias e técnicas de intervenção nos corpos de tal modo que já não sejam mais corpos de sujeitos determinados pelas suas histórias e seus gozos, como se fosse possível uma sociedade de seres humanos que não mais se angustiassem - se, com Freud (1937/2018), identificamos a angústia como necessariamente referida à sexuação.

Nicolas é uma criança pequena que, com seu trabalho em análise, pode falar de suas angústias. Se esse trabalho foi interrompido no momento em que se identificava mais com o pai - dando-lhe acesso a uma identificação estruturante, como já observava Freud (1921/1979) em 1921 -, como pudemos observar, isso ainda não explicita o que escolherá ser quando adulto. Como vimos, a própria WPATH indica que muitas crianças trans podem se tornar homens ou mulheres adultos cisgênero. Assim, deixemos com que possam se posicionar, do jeito como pretenderem fazê-lo. 


\section{Outro Modo de Intervenção}

É muito difícil, para nós, analistas, homens ou mulheres, com experiência, não julgar um caso que está começando a funcionar e elaborar sua análise, sem lembrar, a propósito dele, de outros casos. Qualquer que seja nossa pretensa liberdade - pois é impossível acreditar nessa liberdade -, é evidente que não podemos nos desembaraçar do que é nossa experiência. Freud insiste muito sobre esse ponto e, se isso fosse entendido, talvez indicasse uma via, apontando para um outro modo de intervenção. (Lacan, 1975, p. 8, Grifo nosso)

“Outro modo de intervenção", como sabemos, foi o que Lacan passou a construir, nos anos 1970, com o nó borromeano. O real é três, Lacan (2018) identificará com o seu dizer no Seminário 21: Os não tolos erram, e "ele insiste ao ponto de estar marcado na língua”. O real não acrescenta, não é o terceiro. Tudo que eles, os registros - real, simbólico e imaginário -, têm de real, é que cada um é um. E é desse dizer que não supõe nada, senão que triplo é o real, que Lacan avança para a questão da não relação enquanto ela toca, especificamente, isso que é a subjetivação do sexual. O imaginário obscurece o real da não relação sexual; o simbólico oferece "uma multidão de substâncias surgindo como substitutas à única própria, a do impossível de se falar dela por ser real" (Lacan, 2003, p. 266);, enquanto que o dizer impossível do sexo implica modos de subjetivação de cada sujeito. O manejo clínico do tratamento do real na posição do falasser é o que Lacan propõe mostrar com a "realidade operatória" (Lacan, 2015) da topologia borromeana. De tal maneira que, o parlêtre, o falasser, é "um inconsciente que é um saber falado. É um saber inscrito a partir do corpo a corpo com lalíngua primeira, surgido, portanto, do laço, ou, se preferirem, do banho obsceno e que vale apenas para um" (Soler, 2010).

Prates (2017), seguindo o arcabouço lacaniano, aponta que “Há do Um” [Il y a de l’Un] (Lacan, 2018), sempre ímpar, uma impossibilidade de alcançar o dois. O impasse inverificável do sexo, correspondendo a dois modos de gozo, todo fálico e não-todo fálico, incomensuráveis e irremediavelmente distintos, faz um dois que não é binário, porque é um dois constituído de um Um e do impossível (e.g. Alberti, 2017).

Associamo-lo à história de Manuel (Battista, 2019), que demonstra a maneira como a clínica com crianças atualiza-se frente às questões de gênero. Ela parece contestar a premissa freudiana da universalidade do falo, principal característica da "organização genital infantil", a qual consiste no fato de que, "para ambos os sexos, apenas um genital, o masculino, entra em consideração. Não há, portanto, uma primazia genital, mas uma primazia do falo" (Freud, 1923/2011, p. 171, Grifo do autor). No entanto, o que se evidencia é um questionamento em relação à binaridade imposta pelo discurso: "meninos têm pênis e meninas têm vagina". Insistindo em designar a diferença, até que ponto não se dificulta à criança o acesso ao impossível de sua designação? Quer dizer, apenas o falo é o significante que pode fazer a significação da falta (Lacan. 1998b) e que permite ao sujeito o acesso a um ponto para o qual não há significante algum, o ponto em que o sexual como tal não se faz representar no inconsciente (Elia, 1995). Contudo, se a questão está evidentemente no sujeito, não é sem relação com o discurso corrente.

Do jeito como a questão é tratada hoje, a divisão proposta por Lacan (2018) entre o lado homem e o lado mulher, lerse-ia: do lado homem, temos o necessário e o possível, em que o saber é corte disfarçado de fechamento, fazendo com que o homem abandone o impossível. Enquanto isso, aquilo que, do lado mulher, seria o impossível e o contingente, no qual o saber inconsciente é um conjunto aberto, ou seja, uma classe paradoxal que não se fecha, acaba fechando-se novamente no discurso, levando à misoginia e à segregação. Prates (2017) faz, então, uma ligação do saber, mas não com o desejo, com o horror e sua paixão correspondente, a paixão da ignorância, diante da qual cada discurso escreverá sua modalidade de fechamento e negação sistemática na abertura estrutural do inconsciente não-todo.

Compartilhamos o presente trabalho como uma forma de testemunhar o que Nicolas pode nos ensinar, num momento tão generificado de infâncias rosa ou azul, de princesas ou heróis, que nos possibilite avançar no que seriam "infâncias possíveis" (Tajer, 2017), entendendo a clínica como “lócus que solapa qualquer horizonte normativo, dado que dá espaço ao contingente que advém do inconsciente" (Ambra, 2016, p. 108).

\section{Considerações Finais}

A palavra pródromo, aqui presente - criança é trans? prolegômenos psicanalíticos -, visa a sinalizar que é preciso que comecemos a falar, questionar, não saber, produzir saber e compartilhar questões nessa temática que urge! Um imperativo ético para continuar sustentando a política da psicanálise diante, inclusive, da medicina. Como diria Porchat (2014), não nos furtar à responsabilidade social decorrente do fato de que a criança sozinha inevitavelmente confronta-se com "a sociedade e seus preconceitos, suas limitações de ordem ideológica e política” (p. 78).

Face às mudanças sociais de sua época, Freud repensava a base epistemológica da psicanálise, e Lacan não se furtava de fazer o mesmo frente às novas influências conceituais, de modo que ambos inscrevem a psicanálise no questionamento 
científico, posto que aberta à refutação. De fato, ainda que tentemos tapar o sol com a peneira, a clínica contemporânea articulase com todo um conjunto de novas formas de sexualidades que, de alguma maneira, nos levam ao reconhecimento de que todo processo de sexuação sempre se inscreve em normatizações e jogos de poder particulares (Ayouch, 2015). De tal maneira que, se a divisão binária de gêneros bem como de sexos é uma construção social (Laqueur, 2001). Uma criança que faz ou deseja algo que a inclui numa categoria de não conformidade de gênero não prova que ela seja uma criança trans, nem que não o será.

\section{Referências}

Alberti, S. (2000). Psicanálise, a última flor da medicina. In S. Alberti \& L. Elia (Orgs.), Pesquisa e clínica em psicanálise (pp. 37-56). Rio de Janeiro: Marca d'Água.

Alberti, S. (2017). Dois. In M. Daquino (Org.), A Diferença sexual: Gênero e psicanálise (pp. 77-94). São Paulo: Agente Publicações.

Ambra, P. (2016). A psicanálise é cisnormativa? Palavra política, ética da fala e a questão do patológico. Periódicus: Revista de Estudos Indisciplinares em Gêneros e Sexualidades, 5(1), 101-120.

Ayouch, T. (2015). Psicanálise e transexualismo. Desconstruindo gêneros e patologias com Judith Butler [Resenha]. Jornal de Psicanálise, 48(88), 329-332.

American Psychological Association [APA]. (2015). Guidelines for psychological practice with transgender and gender nonconforming people. American Psychologist, 70(9), 832-864. DOI: 10.1037/a0039906

Battista, J. (2019). A violência de gênero: Liberdade de escolha e escolha forçada. In A. Quinet \& S. Alberti (Orgs.), Sexuação e identidade (pp. 347-352). Rio de Janeiro:Atos \& Divãs.

Barros, M. (2016). O livro das ignorãças. Rio de Janeiro: Alfaguara.

Bourcier, M. H. (2014). Prefácio. In B. Preciado, Manifesto contrassexual (pp. 9-15). São Paulo: n-1 edições.

Braunstein, N. A. (2016). Structures cliniques ou positions subjectives. Analyse Freudienne Presse, (1), 39-57. Link

Celes, L. A. (2005). Psicanálise é trabalho de fazer falar, e fazer ouvir. Psychê, 9(16), 25-48.

Elia, L. (1995). Corpo e sexualidade em Freud e Lacan. Rio de Janeiro: Uapê.

Elia, L. (2000). Psicanálise: clínica e pesquisa. In S. Alberti \& L. Elia (Orgs.), Pesquisa e clínica em psicanálise (pp. 19-36). Rio de Janeiro: Marca d'Água.

Elia, L. (2005). O sujeito, o real e o social. Link

Figueiredo, A. C. (1997). Vastas confusões e atendimentos imperfeitos. Rio de Janeiro: Relume Dumará.

Fraga, M. L. (mar. 2014). A visão política de Thomas Hobbes [Web log Post]. Link

Freud, S. (1974). O mal-estar na civilização. In J. Strachey (Ed.), Edição Standard Brasileira das Obras Psicológicas Completas de Sigmund Freud (Vol. 21, pp. 81-171). Rio de Janeiro: Imago. (Originalmente publicado em 1930)

Freud, S. (1979). Psicología de las masas y análisis del yo. In S. Freud, Obras completas (pp. 63-136). Buenos Aires: Amorrortu. (Originalmente publicado em 1921)

Freud, S. (2011). O Eu e o Id. In S. Freud, Obras completas de Sigmund Freud (Vol. 16, pp. 13-74). São Paulo: Companhia das Letras. (Originalmente publicado em 1923) 
Freud, S. (2016). Três ensaios sobre a teoria da sexualidade. In S. Freud, Obras completas de Sigmund Freud (Vol. 6, pp. 13-172). São Paulo: Companhia das Letras. (Originalmente publicado em 1905)

Freud, S. (2018). Análise terminável e interminável. In S. Freud, Obras completas de Sigmund Freud (Vol. 19, pp. 274-326). São Paulo: Companhia das Letras. (Originalmente publicado em 1937)

Giaretta, V., \& Silva, M. R. (2019). Os indicadores de intersubjetividade e sua potência na clínica de crianças. Estudos e pesquisas em psicologia,19(1), 127-146. Link

Lacan, J. (1975). Conferencia en Ginebra sobre el síntoma. Link

Lacan, J. (1992). O Seminário, livro 17: O avesso (1969-1970). Rio de Janeiro: Jorge Zahar.

Lacan, J. (1996). O Seminário, livro 1: Os escritos técnicos de Freud (1953-1954). Rio de Janeiro: Jorge Zahar.

Lacan, J. (1998a). Função e campo da fala e da linguagem em psicanálise (1953). In J. Lacan, Escritos (pp. 238-324). Rio de Janeiro: Jorge Zahar.

Lacan. J. (1998b). A significação do falo. In J. Lacan, Escritos (pp. 55-62). Rio de Janeiro, RJ: Jorge Zahar.

Lacan, J. (2003). Posfácio ao Seminário 11 (1973). In J. Lacan, Outros escritos (pp. 503-507). Rio de Janeiro: Jorge Zahar.

Lacan, J. (2005). O Seminário, livro 10: A angústia (1962-1963). Rio de Janeiro: Jorge Zahar.

Lacan, J. (2006). O Seminário, livro 14: A lógica da fantasia (1966-1967). Recife: Centro de Estudos Freudianos do Recife.

Lacan, J. (2012). O Seminário, livro 19: ... ou pior (1971-1972). Rio de Janeiro: Jorge Zahar.

Lacan, J. (2015). Le seminaire, livre XXII: RSI (1974-1975) [Seminário inédito]. Link

Lacan, J. (2018). O Seminário, livro 21: Os não tolos erram (1973-1974). Porto Alegre, RS: Editora Fi.

Laqueur, T. (2001). Inventando o sexo: Corpo e gênero dos gregos a Freud. Rio de Janeiro: Relume Dumará. (originalmente publicado em 1990)

Laufer, L. (2017). Feminismos e psicanálise. In Universidade de São Paulo (Org.), I Colóquio psicanálise, gênero e feminismos: Perspectivas. São Paulo, SP: USP.

Porchat, P. (2014). Psicanálise e transexualismo: Desconsiderando gêneros e patologias com Judith Butler. Curitiba: Juruá.

Prates, A. L. (2017). Heresia lacaniana: Um equívoco que dá asas ao novo amor. São Paulo, SP: Fórum do Campo Lacaniano de São Paulo.

Preciado, B. (2014). Manifesto contrassexual. São Paulo: n-1 edições.

Soler, C. (2010). O corpo falante. Caderno de stylus, 1, 09-29.

Tajer, D. (2017). Algunas consideraciones éticas y clínicas sobre las infancias trans. In I. Meler (Org.), Psicoanálisis y género. Escritos sobre el amor, el trabajo, la sexualidad y la violencia (pp.277-294). Buenos Aires: Paidós.

Turban, J., Ferraiolo, T., Martin, A., \& Olezeski, C. (2017). Ten things transgender and gender nonconforming youth want their doctors to know. Journal of the American Academy of Child \& Adolescent Psychiatry, 56(4). Link 
World Professional Association for Transgender Health [WPATH]. (2012). Normas de atenção à saúde das pessoas trans e com variabilidade de gênero. Link

\section{Como citar:}

Alberti, S., \& Silva, H. F. (2020). Questões da Disforia de Gênero na Infância: Entre Psicanálise e Medicina. Revista Subjetividades, 20(Esp 2. O Contemporâneo à Luz da Psicanálise), e8822. http://doi.org/10.5020/23590777.rs.v20iEsp2.e8822

\section{Endereço para correspondência}

Sonia Alberti

E-mail: sonialberti@gmail.com

Heloene Ferreira da Silva

E-mail: heloeneferreira@hotmail.com 